\title{
EFEITO DA ACIDIFICAÇÃO, FERMENTAÇÃO E ADIÇÃO DE CÁLCIO NA QUALIDADE DE COUVE-FLOR (Brassica oleraceae L.) PROCESSADA PELO CALOR ${ }^{1}$
}

\author{
J.N. NOGUEIRA; P.R. CANTARELli; C.R. GALlO; I.A.M. MORENO \\ Dep. de Ciencia e Tecnologia Agroindustrial da ESALQ/USP, Caixa Postal, 9 - CEP: 13418-900-Piracicaba,SP. \\ F.C.A.V. MATSUURA \\ Bolsista de Iniciaçāo Cientefica da FAPESP.
}

\begin{abstract}
RESUMO: O presente trabalho foi desenvolvido com o objetivo de fornecer informaçōes, não encontradas na literatura, sobre o efeito da acidificação (cinco ácidos orgânicos), fermentação e adição de cálcio na qualidade de couve-flor (cultivar Shiromaru III), processada pelo calor. A qualidade da couve-flor processada foi avaliada através de análise física, química, microbiológica e sensorial, após dois meses de armazenamento à temperatura ambiente. Os resultados mostraram a possibilidade de processar couve-flor enlatada, de alta qualidade, em pequenas indústrias, com redução de gastos em equipamentos, instalaçōes e energia. $O$ procedimento da acidificação oferece também uma segurança maior para o consumidor, pois elimina possíveis riscos de incidência do botulismo.

Descritores: couve-flor, acidificação, processamento térmico, fermentação de hortaliça.
\end{abstract}

\section{EFFECT OF ACIDIFICATION, FERMENTATION AND ADDITION OF CALCIUM ON TIIE QUALITY OF CANNED CAULIFLOWER (Brassica oleraceae L.)}

\begin{abstract}
ARSTRACT: The present work was developed to provide information currently lacking in the literature on the effect of acidification (five organic acids), fermentation and addition of calcium on the quality of canned cauliflower (cultivar Shiromaru III). Quality evaluation of the processed cauliflowers was determined by physical, chemical, microbiological and sensorial analysis, after a two month storage period at room temperature. The results showed the possibility of processing high quality canned cauliflowers by small canneries with low cost equipment and less energy requirement. The acidification procedure also implies in minor risks due to potential botulism incidence. Key Words: cauliflower, acidification, thermal processing, vegetable fermentation.
\end{abstract}

\section{INTRODUÇÃO}

A maioria das hortaliças é classificada entre os alimentos considerados de baixa acidez, ou seja, os que apresentam pH acima de 4,6 (FOOD AND DRUG ADMINISTRATION, 1976). Estes alimentos, quando não submetidos a uma esterilização comercial adequada (temperaturas acima de $100^{\circ} \mathrm{C}$ ), estão sujeitos ao desenvolvimento do Clostridium botulinum bactéria anaeróbica esporulada capaz de produzir uma neurotoxina altamente perigosa para o homem.

Nos Estados Unidos da América, os casos de botulismo decorrem, na maioria das vezes da ingestão de conservas caseiras, nas quais foi produzida a potente neurotoxina do Clostridium botulinum (FRAZIER, 1967; AYRES, 1975). No Brasil, a ocorrência de botulismo tem sido raramente relatada. Esta constatação, sem dúvida nenhuma, reflete muito mais uma consequência da falta de divulgação de estatística a respeito do fato do que propriamente da ausência do problema no país.

GRANER (1976) chamou a atenção para o perigo representado pela elaboração inadequada de conservas caseiras, uma vez que, em nosso meio, podem ser encontradas em livros, revistas e jornais, receitas que não levam em consideração a classificação dos alimentos quanto ao seu pH e que recomendam um processamento térmico à cerca de $100^{\circ} \mathrm{C}$ para alimentos de baixa acidez, sem uma prévia acidificação. Pelo que foi exposto, certos cuidados são de grande importância na elaboração de conservas, no sentido de ser impedida a formação nestas, da toxina botulínica. Assim, quando se trata da conservação de alimentos pelo calor (apertização), a acidez do produto-a ser processado termicamente $e$ fator determinante do

${ }^{1}$ Pesquisa financiada pela FAPESP.

Sci. agric., Piracicaba. 50(1):127-139, fev./maio, 1993 
tipo de tratamento a ser empregado: temperaturas próximas de $100^{\circ} \mathrm{C}$ (banho-maria), para alimentos ácidos (pH até 4,6), e temperaturas acima de $100^{\circ} \mathrm{C}$ (autoclaves), para alimentos pouco ácidos (pH maior que 4,6). Neste caso, como alternativa, a esterilização pode ser feita em banho-maria, desde que o $\mathrm{pH}$ do produto seja reduzido pelo emprego de acidulantes permitidos em alimentos, como é feito, por exemplo, no processamento do palmito (NOGUEIRA, 1979).

As hortaliças têm sido comumente processadas empregando-se métodos que requerem grandes gastos de energia, como o congelamento e - processamento térmico em autoclaves (FERMENTATION, 1980). Considerando o alto custo da energia e dos equipamentos, KOSUP; SISTRUNK (1982) sugeriram que estudos devem ser desenvolvidos no sentido de se encontrar métodos alternativos que reduzam os custos e mantenham a qualidade desses produtos após o processamento. Segundo SUPRAN et al. (1966), KARMAS (1975) e FLEMING; McFEETERS (1981), a fermentação e a acidificação parecem ser os métodos indicados para se atingir aqueles objetivos. A fermentação tem sido também utilizada para melhorar certos atributos de qualidade, como o sabor e a textura (KOTZEKIDOU; ROUKAS, 1987).

Muitas hortaliças não podem ser processadas termicamente, devido à perda exagerada de textura após a esterilização. Segundo VAN BUREN (1979), a textura é uma importante caraterística dos alimentos e o controle ou melhoria deste atributo constitui um dos principais objetivos da moderna tecnologia de alimentos.

A utilização de cálcio tem sido relatada como um importante método para manter a textura de vegetais, durante o processamento (VAN BUREN, 1968 e 1979). A ação deste composto está relacionada à sua interação com a pectina dos vegetais, dando formação ao pectato de cálcio que é estável ao calor.

Considerando todos os fatores mencionados, os autores se propuseram a desenvolver um estudo sobre o processamento térmico de couve-flor acidificada, pelo emprego de cinco ácidos orgânicos, ou por via fermentativa, tendo em vista os seguintes objctivos: (a) estudar o efeito dos ácidos e da fermentação nas propricdades organolépticas do produto processado; (b) determinar o efeito dos ácidos e da fermentação nas características físicas e químicas da hortaliça processada; e (c) verificar o cfeito da adição de cálcio na preservação da textura da couve-flor, após o processamento.

\section{MATERIAL E MÉTODOS}

\section{Matéria-Prima}

Neste trabalho, foi estudada couve-flor (Brassica oleraceae L.) cultivar Shiromaru III, proveniente do município de Piedade,SP. A matéria-prima foi obtida de produção comercial, colhida aos 120 dias de ciclo da cultura. Imediatamente após a colheita, as couves-flores foram preparadas para o processamento.

\section{Análises da matéria-prima.}

a) $\mathrm{pH}$ : determinado em potenciômetro Alphalab, modelo PA-200.

b) Brix: obtido através de leitura direta feita em refratômetro ATAGO modelo $\mathrm{N}-1$, utilizando o suco resultante da trituração da couve-flor.

c) Textura: avaliada objetivamente no "Texture Testing System" (Kramer Shear Press) modelo TP2 com registrador (escala 1000), utilizando a célula padrão CS-1. O anel sensor empregado foi o de $30001 \mathrm{bs}$ e a velocidade do pistão, de $20 \mathrm{~cm} / \mathrm{min}$. Para as determinações empregaram-se amostras de $50 \mathrm{~g}$ de couve-flor, preparadas da mesma forma que foram processadas.

\section{Processamento}

A Figura 1 mostra o fluxograma das operações utilizadas no processamento. Todas as salmouras utilizadas no experimento foram preparadas com cloreto de sódio não iodado (sal granulado), para evitar possíveis efeitos adversos à cor e ao sabor do produto processado (SIMONS et al., 1955).

\section{Preparo}

Inicialmente, o preparo foi efetuado pela retirada das folhas que envolvem a couve-flor. $\mathrm{Em}$ seguida, seccionaram-se as inflorescências do talo principal, empregando-se, para esta operação, facas de aço inoxidável. O material, assim preparado foi mantido em solução de espera (salmoura a $1,5 \%$ ), 
até que fosse aplicada a operação seguinte.

\section{Branqueamento}

O branqueamento foi feito por imersão das couves-flores em água fervente $\left(97^{\circ} \mathrm{C}\right)$, durante três minutos. Após o branqueamento, as couvesflor foram rapidamente resfriadas em água fria, à temperatura ambiente.

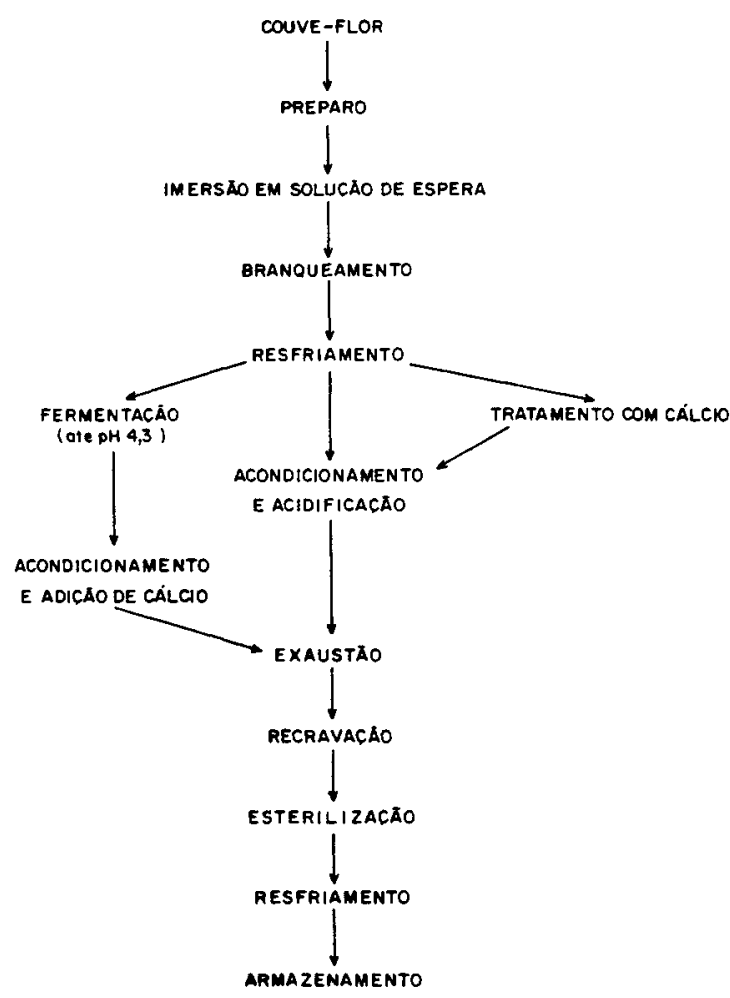

Figura 1 - Fluxograma das operações utilizadas no processamento da couve-flor.

\section{Tratamento com cálcio}

Após o branqueamento e resfriamento, parte das couves-flores foi tratada com cálcio por imersão em solução contendo $0,5 \%$ de cloreto de cálcio (à temperatura de $50^{\circ} \mathrm{C}$ ) durante 10 minutos. Após o tratamento, as couves-flores foram drenadas e processadas de acordo com o esquema apresentado na Figura 1.

\section{Fermentação da couve-flor}

A outra parte das couves-flores, após o branqueamento e o resfriamento, foi submetida a uma fermentação láctica a $37-39^{\circ} \mathrm{C}$ inoculando-se uma cultura de Lactobacillus bulgaricus e Streptococcus thermophilus (cultura de nome comercial RICH). A fermentação foi conduzida em salmoura a $1,5 \%$, até que as couves-flores atingissem $\mathrm{pH} 4,3$, após o que foram drenadas e processadas de acordo com o esquema apresentado na Figura 1. Metade das couves-flores fermentadas foi também submetida ao tratamento com cálcio, adicionando-se $0,2 \%$ de cloreto de cálcio à salmoura em que foram acondicionadas.

\section{Acondicionamento e acidificação}

O acondicionamento foi feito em latas de $1 \mathrm{~kg}(99,5 \times 118,0 \mathrm{~mm})$, revestidas internamente com verniz epóxi. Em cada lata foram colocados $350 \mathrm{~g}$ de couve-flor e $535 \mathrm{ml}$ de salmoura, contendo $1,5 \%$ de cloreto de sódio e uma certa porcentagem de ácido, concentração esta que foi previamente calculada para se obter pH 4,3, após o estabelecimento do equilíbrio da conserva.

A concentração do ácido na salmoura foi calculada pela curva de acidificação da couve-flor, previamente determinada de acordo com a técnica estabelecida por ZAPATA; QUAST (1975). A acidificação da couve-flor foi feita com o emprego de cinco ácidos orgânicos: cítrico (monoidratado), tartárico, acético, málico e lático.

As couve-flores acidificadas por fermentação foram acondicionadas empregando-se a salmoura da própria fermentação que já apresentava $\mathrm{pH}$ baixo o suficiente para a obtenção do $\mathrm{pH}$ de equilibrio desejado.

O esquema geral dos tratamentos utilizados no processamento da couve-flor está representado na Figura 2.

\section{Exaustão e recravação}

As latas, devidamente preenchidas, com as tampas soltas sobrepostas, foram parcialmente imersas em água fervente, ficando a parte superior 
das mesmas à cerca de $3 \mathrm{~cm}$ do nível da água. Os recipientes foram aquecidos até que a temperatura da salmoura, no centro geométrico da lata, atingisse $85^{\circ} \mathrm{C}$. Completada a exaustão, as latas foram imediatamente recravadas e conduzidas à esterilização.

\section{Esterilizaçāo}

A esterilização foi feita por imersão das latas em água fervente, durante 30 minutos.

\section{Resfriamento e armazenamento}

Imediatamente após a esterilização, as latas foram resfriadas por imersão $\mathrm{em}$ tanque com circulação de água fria. Foram processadas um total de 10 latas para cada tratamento (5 para cada repetição).

\section{Análises da couve-flor processada}

A couve-flor processada foi analisada após dois meses de armazenamento à temperatura ambiente.

Análises físicas e químicas: peso líquido e drenado, $\mathrm{pH}$ de equilibrio, acidez total, aspecto da salmoura e aspecto interno da lata.

a) Peso líquido: constitui-se do peso bruto descontado do peso da lata vazia, limpa e seca. Foi determinado em balança com precisão de $0,01 \mathrm{~g}$.

b) Peso drenado: determinado com um conjunto constituído de peneira $n^{0} 8$ e fundo, em balança com precisão de $0,01 \mathrm{~g}$. Todo o conteúdo da lata foi invertido no conjunto peneira-fundo, inclinandose depois ligeiramente a peneira sobre o fundo e deixando-se drenar durante dois minutos. O peso da peneira mais o peso do produto menos o peso da peneira, constitui o peso drenado.

c) Vácuo: determinado diretamente por meio de um vacuômetro Marshalltown em pol $\mathrm{Hg}$. A tampa do recipiente foi ligeiramente umedecida e o vacuômetro comprimido na mesma em um ponto próximo da borda, perfurando-a. Procedeu-se, então, a leitura da deflexão da agulha.

d) $\mathrm{pH}$ de equilibrio: đeterminado em potenciômetro Alphalab modelo PA 200, utilizando-se apenas a salmoura de acondicionamento, uma vez que, após dois meses de armazenamento, a conserva já tinha atingido o seu ponto de equilíbrio.

e) Brix de equilíbrio: determinado em refratômetro ATAGO modelo $\mathrm{N}-1$, utilizando-se a salmoura de acondicionamento.

f) Acidez total: determinada através da titulação da salmoura de acondicionamento com hidróxido de sódio $0,1 \mathrm{~N}$, na presença de fenolftaleína a $1 \%$.

g) Aspecto interno da lata: avaliação visual do grau de corrosão interna da lata, utilizando-se a seguinte escala: (1) sem corrosão; (2) corrosão ligeira; (3) corrosão regular; (4) corrosão intensa.

h) Aspecto da salmoura: avaliação visual do grau de turvação da salmoura de acondicionamento, de acordo com a seguinte escala numérica: (1) $\mathrm{sem}$ turvação; (2) pequena turvação; (3) turvação média; (4) turva; (5) muito turva. Para a avaliação, as salmouras foram colocadas em provetas de 250 $\mathrm{ml}$ não graduadas e examinadas após 30 minutos de repouso.

\section{Análise organoleptica}

As couves-flores processadas, utilizando os cinco ácidos orgânicos, e as acidificadas por fermentação, foram avaliadas em termos de cor, sabor e textura por uma equipe de oito julgadores, previamente selecionada e treinada para este tipo de avaliação (GIRARDOT et al., 1952; DAWSON, 1964 e MARTIN, 1973). Atributos de qualidade como cor, textura e sabor (especialmente este último), devido à complexidade inerente aos mesmos são, geralmente, avaliados de maneira mais adequada pela análise organoléptica (SAWYER, 1971 e KONIGSBACHER, 1978).

Inicialmente, os julgadores avaliaram a cor, utilizando-se da luz fluorescente do laboratório. A seguir, foi feita a avaliação da textura e do sabor, em cabines dotadas de luz vermelha. O método sensorial empregado foi o da análise descritiva (LARMOND, 1977), utilizandose escala de 9 pontos, desenvolvida especificamente para o teste, para os atributos:

a) cor: (1) sem cor; $(2,3)$ cor fraca); $(4,5,6)$ cor moderada; $(7,8)$ cor intensa; $(9)$ cor muito intensa.

b) textura: (1) muito mole; $(2,3)$ mole; $(4,5,6)$ nem mole, nem firme; $(7,8)$ firme; $(9)$ muito firme. 
c) sabor: (1) sem sabor; $(2,3)$ sabor fraco; $(4,5,6)$ sabor moderado; $(7,8)$ sabor intenso; (9) sabor muito intenso.

Cada amostra, correspondente a cada tratamento, foi servida a cada julgador duas vezes. Em cada sessão de avaliação, foram servidas para cada julgador, 5 amostras que representavam 4 tratamentos escolhidos ao acaso e a referência, perfazendo um total de 6 sessões para a avaliação do experimento. Os tratamentos foram comparados entre si e com a referência que correspondeu à couve-flor processada na mesma data de avaliação sensorial. O processamento seguiu o mesmo esquema dos tratamentos, porém, sem acidificação ou fermentação e sem adição de cálcio. Esta mesma referência foi também utilizada para comparação dos tratamentos na avaliação objetiva da textura.

A qualidade geral de cada amostra foi obtida tomando-se a média aritmética das notas dadas, por julgador, para os atributos cor, textura e sabor, conforme recomendação de GOULD (1968).

\section{Análise objetiva da textura}

O produto processado foi avaliado objetivamente quanto à textura, pclo emprego de "Texture Testing System" (Kramer Shear Press) modelo TP-2, com registrador (escala 300) utilizando célula padrão CS-1, como já foi descrito anteriormente para a matéria-prima.

\section{Análise microbiológica}

Foi feita uma análise microbiológica do produto processado, especialmente quanto à atividade biológica em pH 4.3, conforme técnica descrita por CORLETT; DENNY (1984), buscando principalmente a recuperação de Bacillus (B.coagulans, B.stearothermophilus), que são as bactérias utilizadas como padrão de esterilização comercial para alimentos dessa natureza ( $\mathrm{pH}<4,6$ ).

O meio de cultura utilizado foi o Plate Count Agar (PCA), meio padrão recomendado para estimativa da carga macrobiana total em alimentos. Em condições assépticas, procedeu-se a abertura das latas, a coleta das alíquotas da salmoura, o plaqueamento e a incubação. Não se coletou o próprio alimento, e sim a salmoura, face ao tempo de aproximadamente dois meses decorrido entre o processamento e a análise, o que permite um bom equilibrio entre o alimento e a salmoura.

Para o plaqueamento, alíquotas de $1 \mathrm{ml}$ retiradas diretamente da salmoura das latas $\left(10^{\circ}\right)$, foram utilizadas em duplicata; também se preparou diluição $10^{-1}$, retirando-se alíquota de $10 \mathrm{ml} \mathrm{da}$ salmoura e adicionando-se a $90 \mathrm{ml}$ de água peptonada esterilizada, de onde alíquotas de $1 \mathrm{ml}$, em duplicata, foram utilizadas para o plaqueamento.

Neste ensaio, para uma averiguação mais completa de possíveis microrganismos sobreviventes, foram utilizadas as seguintes variações:

a) Estimativa do número de unidades formadoras de colônias (UFC/ml ou g), em PCA, utilizando-se $10^{\circ}$ e $10^{-1}$, com incubação a $32^{\circ} \mathrm{C} / 24-48 \mathrm{~h}$, para contagem de mesófilos.

b) Estimativa do número de unidades formadoras de colônias (UFC)/ml ou g, em PCA, utilizando-se $10^{\circ}$ e $10^{-1}$, com incubação a $50^{\circ} \mathrm{C} / 24-48 \mathrm{~h}$, para contagem de mesófilos.

b) Estimativa do número de esporos viáveis $/ \mathrm{ml}$ ou $\mathrm{g}$, em PCA, utilizando-se $10^{\circ}$ e $10^{-1}$, com ativação térmica dos esporos a $80^{\circ} \mathrm{C} / 10^{\prime} \mathrm{e}$ incubação a $32^{\circ} \mathrm{C} / 24-48 \mathrm{~h}$ (esporos de mesófilos) e a $50^{\circ} \mathrm{C} / 24$ $48 \mathrm{~h}$ (esporos de termófilos).

Todas as análises do produto processado foram feitas com, no mínimo, duas repetições para cada tratamento.

\section{Análise estatística dos resultados}

A análise estatística foi feita empregandose a análise de variância, com utilização do teste Tukey (GOMES, 1973).

\section{RESULTADOS E DISCUSSÃO}

Os resultados da análise da matéria-prima (Brix, pH e textura) são apresentados na TABELA 1 e Figura 3. A quantidade de ácido necessária

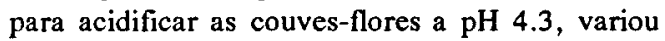
com o tipo de ácido adicionado e seguiu a seguinte ordem decrescente: ácido acético, ácido cítrico, ácido lático, ácido málico e ácido tartárico (Figura 4). Essa variação é decorrente da influência do poder tampão da couve-flor para cada ácido e da constante de dissociação do ácido empregado. 
TABELA 1 - Características químicas e físicas da couve-flor "in natura" (Matćria-prima).

\begin{tabular}{lc}
\hline \hline Características & Valores Mćdios* \\
\hline Sólidos solúveis & 6,70 \\
pH & 6,43 \\
Grancuore & 6,92 \\
\hline \hline
\end{tabular}

* Média de 6 amostras

A acidificação com ácido cítrico foi considerado o melhor tratamento para cor, após a referência, seguido pelo ácido lático, fermentado, ácido acético, ácido tartárico e ácido málico. A fermentação e a adição de cálcio tiveram efcito favorável para a cor das couves-flores processadas (TABELA 2 e Figura 5).

A textura foi significativamente melhorada, tanto com a acidificação como com a fermentação, principalmente para as couves-flores processadas tratadas com cálcio. A variação de textura observada entre os tratamentos e a referência se deve, em grande parte, ao efeito de ligação ("bonding") entre o ácido e as mucilagens (KOTZEKIDOU; ROUKAS, 1987). Já, a diferença de textura entre os tratamentos com e sem cálcio é devida a ação do cálcio como íon-ponte entre as cadeias de pectina, dando formação ao pectato de cálcio que é estável ao tratamento térmico (VAN BUREN, 1968 e 1979).

A avaliação sensorial indicou a seguinte ordem decrescente para o valor de textura (mais firme para menos firme): ácido acćtico, ácido lático, ácido cítrico igual ácido málico, ácido tartárico, fermentado e referência (TABELA 2 e Figura 6). De acordo com os resultados da avaliação objetiva obtidos no "Shear Press" (Figuras 9 e 10), couves-flores, acidificadas com ácido acético, apresentaram textura mais firme seguidas por ácido lático, ácido cítrico, ácido tartárico, ácido málico, fermentado c referência. A interação mais eficiente entre ácido e cálcio para a textura foi observada para a couve-flor acidificada com ácido lático, que apresentou uma melhora de 2,4 vezes $(\mathrm{em} 1 \mathrm{bf} / \mathrm{g})$ naquele atributo de qualidade (Figura 9).

Acidificação com qualquer ácido ou fermentação melhorou o sabor da couve-flor processada. A avaliação sensorial indicou a seguinte ordem decrescente de intensidade de sabor (mais intenso para menos intenso): ácido acético, ácido lático, ácido tartárico, ácido cítrico, ácido málico, fermentado e referência (TABELA 2 e Figura 7). A adição de cálcio e a fermentação não prejudicou o sabor das couves-flores processadas.

$A$ análise sensorial mostrou que a referência foi, dentre todos os tratamentos, a amostra que recebeu a pior avaliação em termos de qualidade geral (TABELA 2 e Figura 8). Os resultados indicaram que exceto para cor, todos os demais atributos de qualidade da couve-flor processada foram significativamente melhorados pcla acidificação e adição de cálcio.

As análises físicas e químicas não mostraram influência significativa dos tratamentos (TABELA 3). O peso drenado teve um pequeno aumento em relação ao peso original das couvesflores, resultado semelhante a SUPRAN et al. (1966). Sólidos solúveis diminuíram no produto processado, devido ao equilibrio que ocorreu entre a couve-flor e a salmoura de acondicionamento. $O$ $\mathrm{pH}$ de equilibrio observado permaneceu ao redor de 4,35 , exceto para o produto fermentado. A acidez total foi maior para a couve-flor acidificada com ácido acético, seguida de ácido lático, ácido cítrico, fermentada, ácido málico, ácido tartárico. A análise microbiológica demonstrou não existir microrganismos viáveis no produto processado.

\section{CONCLUSÕES}

A acidificação com ácido cítrico foi considcrado o melhor tratamento para cor. A fermentação e a adição de cálcio tiveram também efcito favorável para a cor da couve-flor processada. A textura foi significativamente melhorada, tanto com a acidificação como com a fermentação, principalmente para a couve-flor tratada com cálcio. A acidificação com qualquer ácido (especialmente com ácido acético) ou fermentação melhorou o sabor da couve-flor processada.

Os resultados mostraram, portanto, a possibilidade de processar couve-flor enlatada, de alta qualidade, em pequenas indústrias, com rcdução de gastos em equipamentos, instalações e energia, quando comparado com o processo convencional de esterilização em autoclaves. $O$ procedimento da acidificação oferece também uma segurança maior para o consumidor, pois elimina possíveis riscos de incidência do botulismo. 


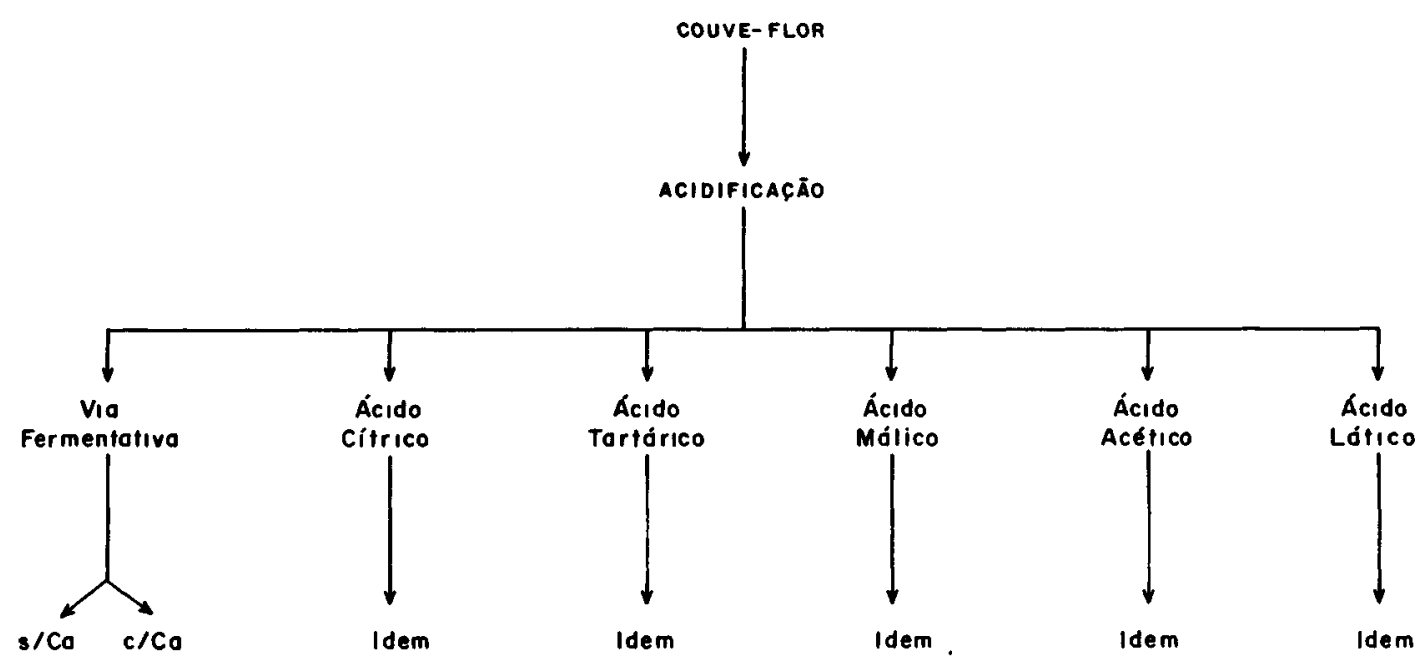

Figura 2 - Esquema geral dos tratamentos utilizados no processamento da couve-flor.

TABELA 2 - Efeito da acidificação e adição de cálcio nas características sensoriais da couve-flor processada (Análise Estatística).

\begin{tabular}{|c|c|c|c|c|}
\hline \multirow[b]{2}{*}{ Tratamentos } & \multicolumn{4}{|c|}{ Média das avaliações (8 julgadores) } \\
\hline & Cor & Textura & Sabor & Qualidade Geral \\
\hline REFERÊNCIA & $8,31 \mathrm{a}$ & $2,06 \mathrm{~h}$ & $4,06 \mathrm{~g}$ & $4,81 \mathrm{~g}$ \\
\hline Ácido Cítrico I & 7,44abc & $4,87 f g$ & $6,37 \mathrm{cde}$ & $6,23 \mathrm{cdef}$ \\
\hline Ácido Cítrico II & $8,25 \mathrm{a}$ & $8,0 \mathrm{ab}$ & $7,87 \mathrm{a}$ & $8,04 a$ \\
\hline Ácido Tartárico I & $5,81 \mathrm{e}$ & $4,75 \mathrm{fg}$ & $6,44 \mathrm{cde}$ & $5,67 \mathrm{defg}$ \\
\hline Ácido Tartárico II & $6,25 \mathrm{de}$ & $6,94 \mathrm{~cd}$ & $6,75 \mathrm{bcd}$ & $6,65 \mathrm{bcde}$ \\
\hline Ácido Lático I & $7,25 \mathrm{bc}$ & $5,62 \mathrm{ef}$ & 7,25abc & $6,71 \mathrm{bcd}$ \\
\hline Ácido Lático II & 7,44abc & $7,44 a b c$ & 7,31abc & $7,40 \mathrm{ab}$ \\
\hline Ácido Acético I & $6,56 \mathrm{cde}$ & $7,19 \mathrm{bc}$ & $7,69 \mathrm{ab}$ & $7,15 \mathrm{abc}$ \\
\hline Ácido Acético II & $8,12 \mathrm{ab}$ & $8,00 \mathrm{ab}$ & $7,56 \mathrm{ab}$ & $7,90 \mathrm{a}$ \\
\hline Ácido Málico I & $5,62 \mathrm{e}$ & $4,87 \mathrm{fg}$ & $6,19 \mathrm{de}$ & $5,58 \mathrm{efg}$ \\
\hline Ácido Málico II & $6,87 \mathrm{~cd}$ & $8,19 a$ & $7,69 \mathrm{ab}$ & $7,58 \mathrm{ab}$ \\
\hline Fermentado I & $6,94 \mathrm{~cd}$ & $4,37 \mathrm{~g}$ & $4,75 \mathrm{fg}$ & $5,35 \mathrm{fg}$ \\
\hline Fermentado II & $7,00 \mathrm{~cd}$ & $6,00 \mathrm{de}$ & $5,69 \mathrm{ef}$ & $6,23 \mathrm{cdef}$ \\
\hline
\end{tabular}

I = sem cálcio; II = com cálcio. Números seguidos da mesma letra não diferem estatisticamnte a nível de $5 \%$. Qualidade geral = média da avaliação de cor, textura e sabor. 


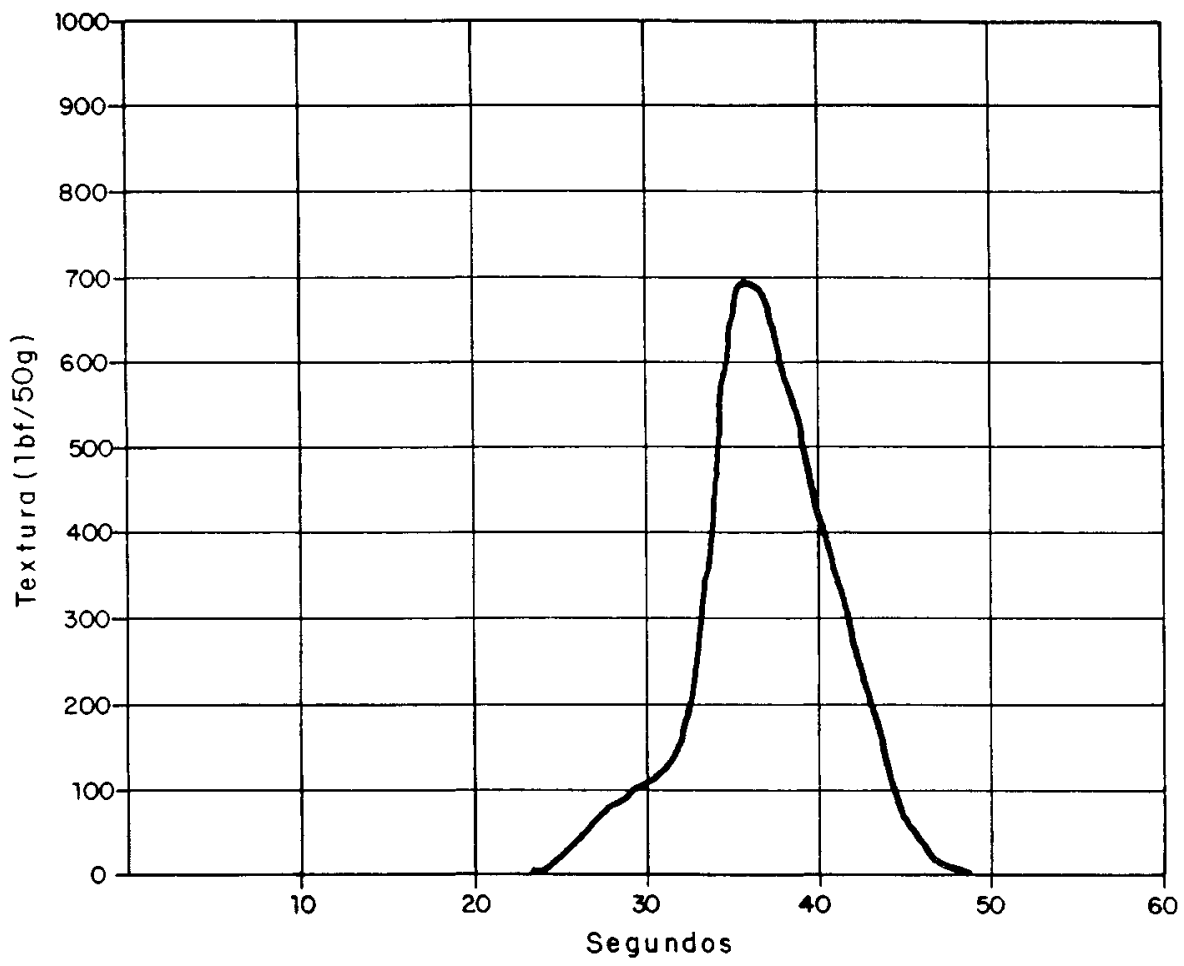

Figura 3 - Curva típica obtida no "Shear Press" da couve-flor "in natura" (Matéria-prima).

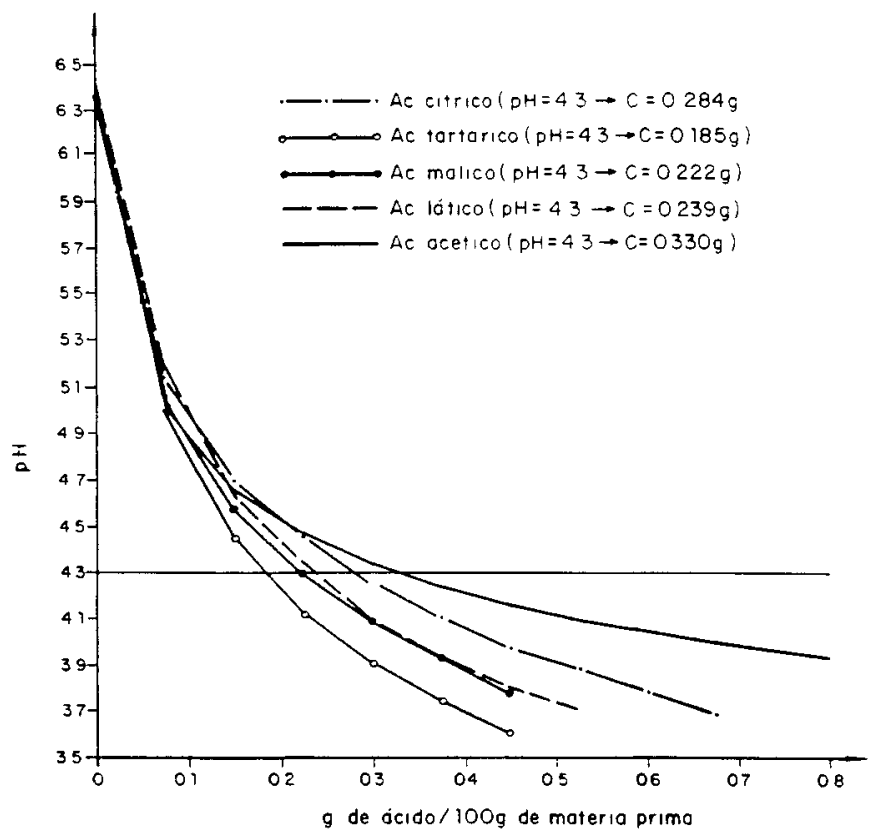

Figura 4 - Curvas de acidificação da couve-flor com cinco ácidos orgânicos.

Sci. agric., Piracicaba. 50(1):127-139, fev./maio, 1993 


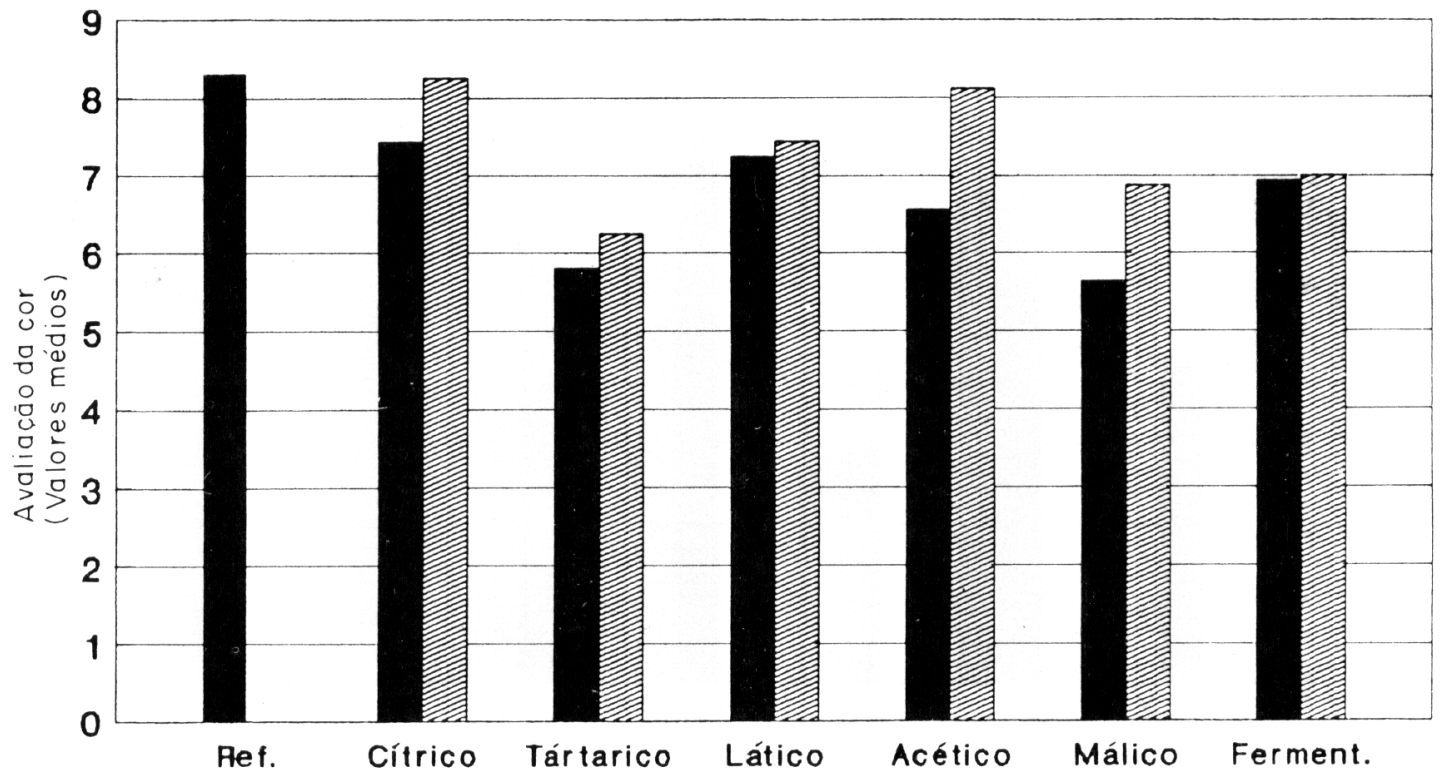

Sem cálcio 䐴 Com cálcio

Figura 5 - Efcito da acidificação e adição de cálcio na cor da couve-flor processada - Avaliação Sensorial.

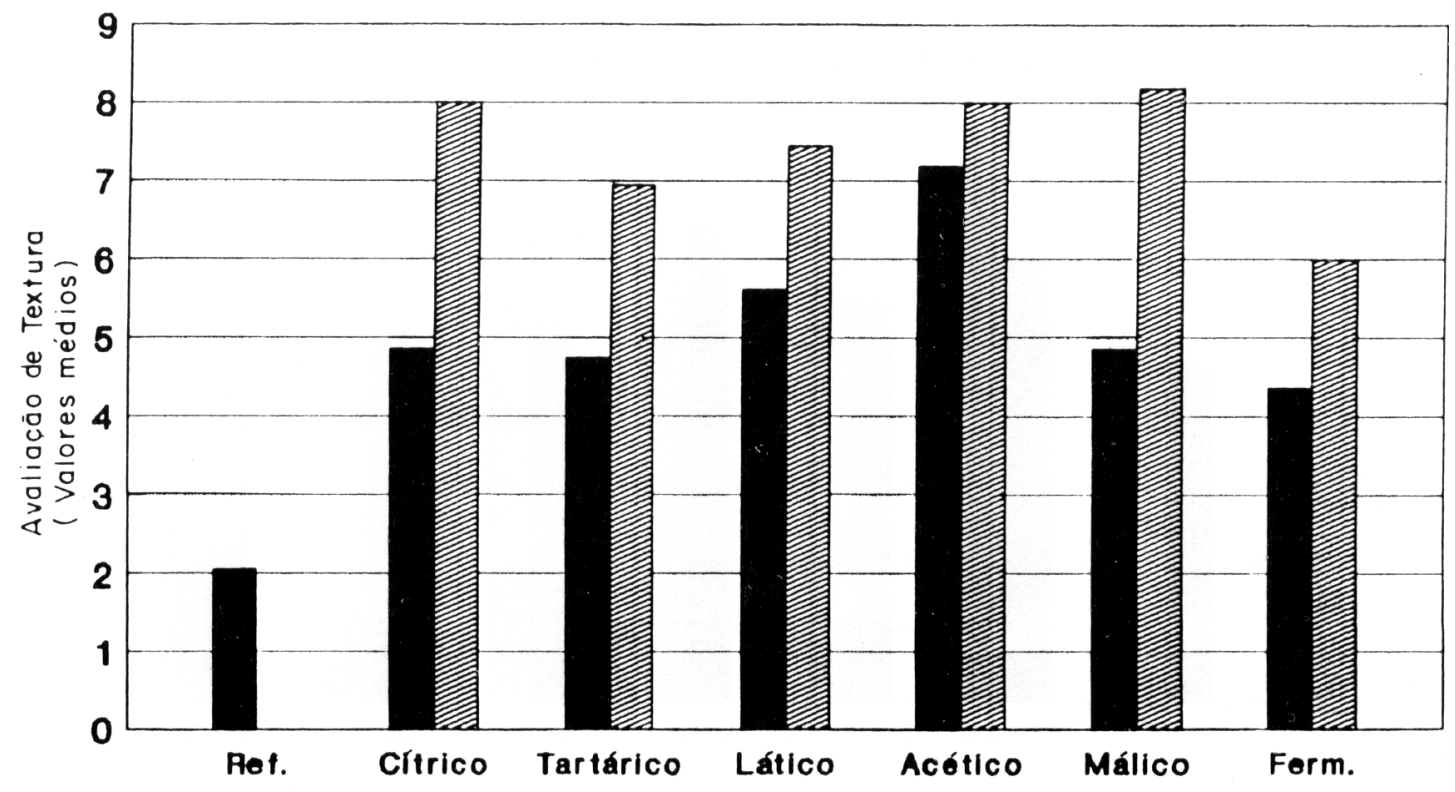

\section{Sem cálcio Com cálclo}

Figura 6 - Ef́cito da acidificação e adição de cáleio na textura da couve-flor processada - Avaliação Sensorial.

Sci. agric., Piracicaba. 50(1):127-139, fev./maio, 1993 


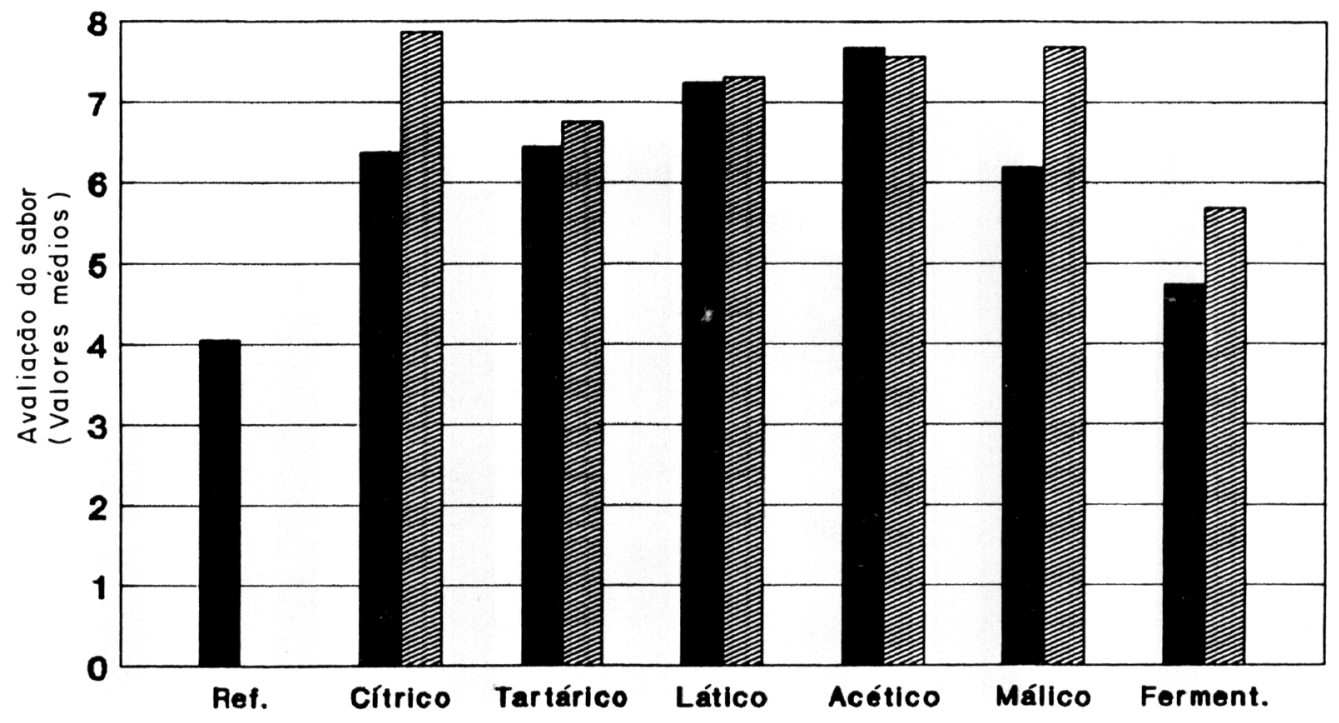

Sem cálcio Wom cálclo

Figura 7 - Efeito da acidificação e adição de cálcio no sabor da couve-flor processada - Avaliação Sensorial.

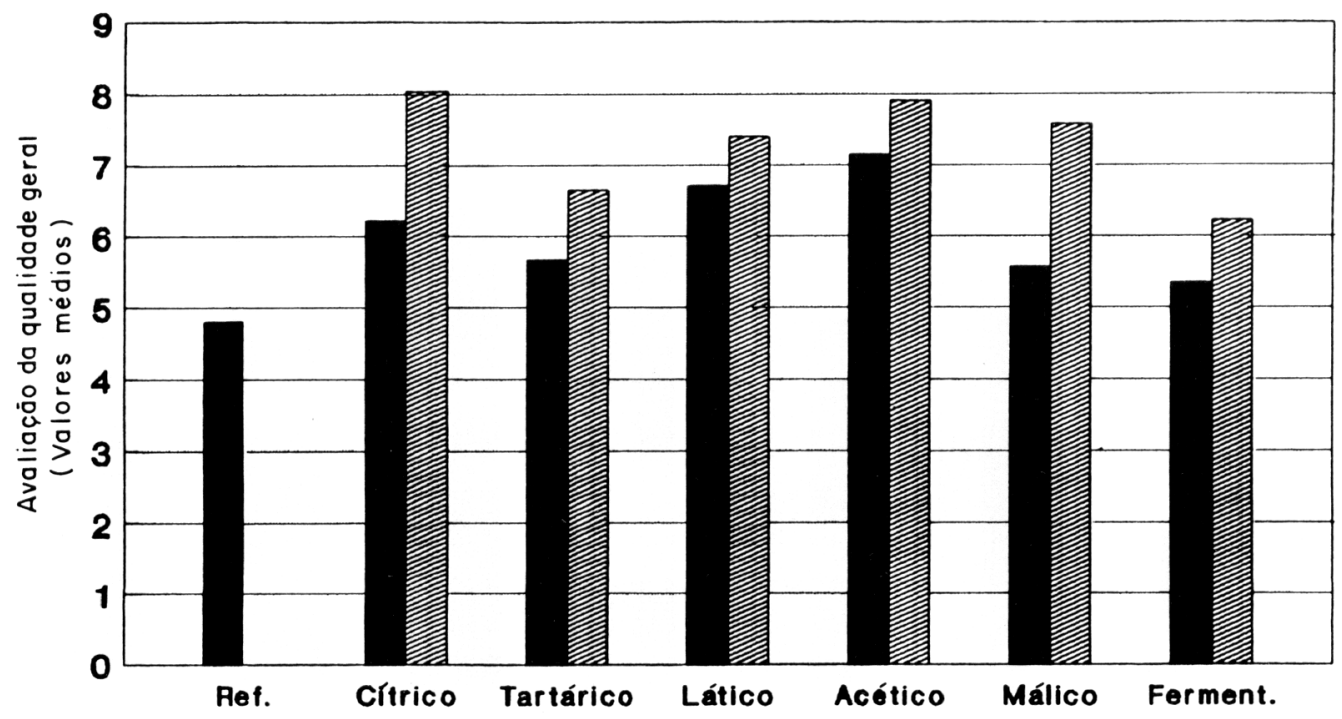

Sem cálcio Wom cálcio

Figura 8 - Efeito da acidificação e adição de cálcio na qualidade geral da couve-flor processada - Avaliação Sensorial.

Sci. agric., Piracicaba. 50(1):127-139, fev./maio, 1993 


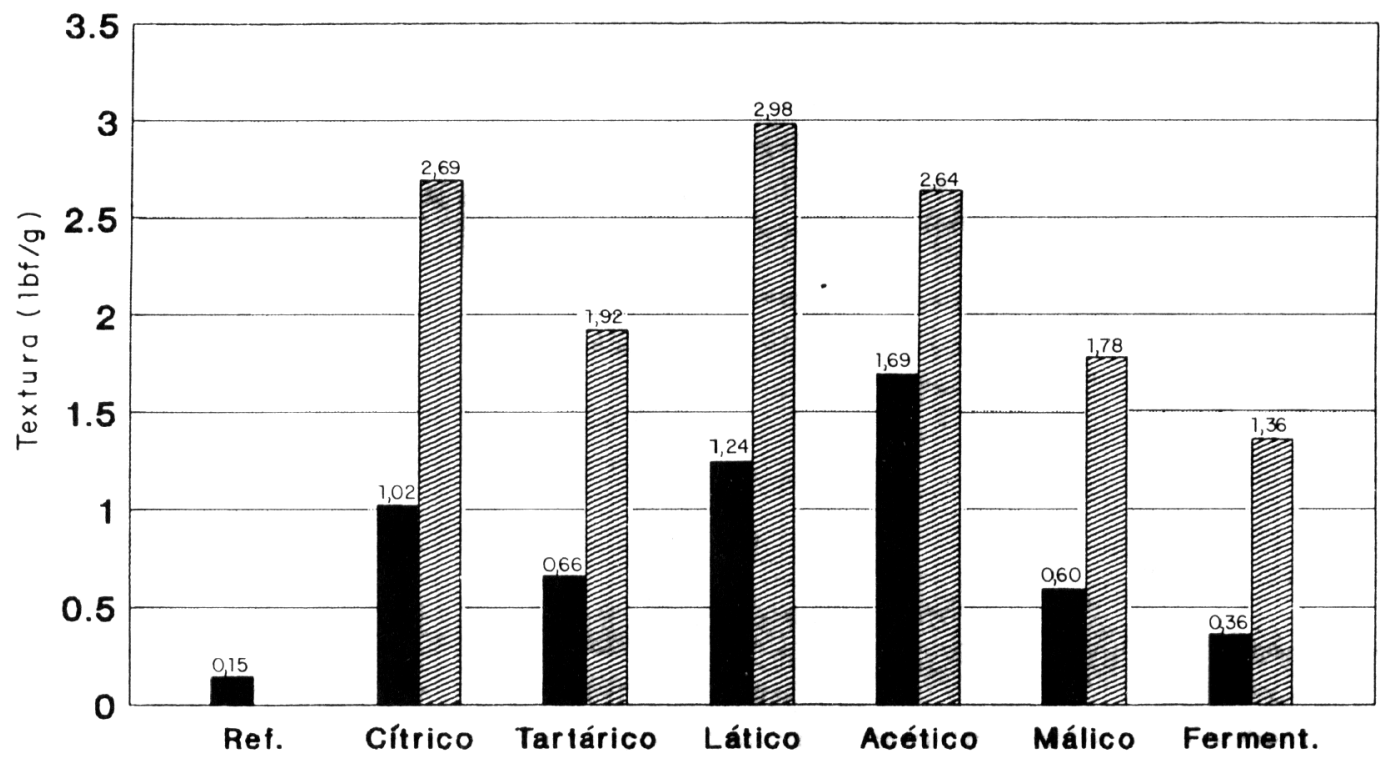

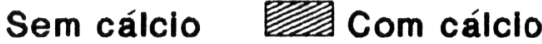

Figura 9 - Efeito da acidificação e adição de cálcio na textura da couve-flor processada - Avaliação Objetiva ("Shear Press").

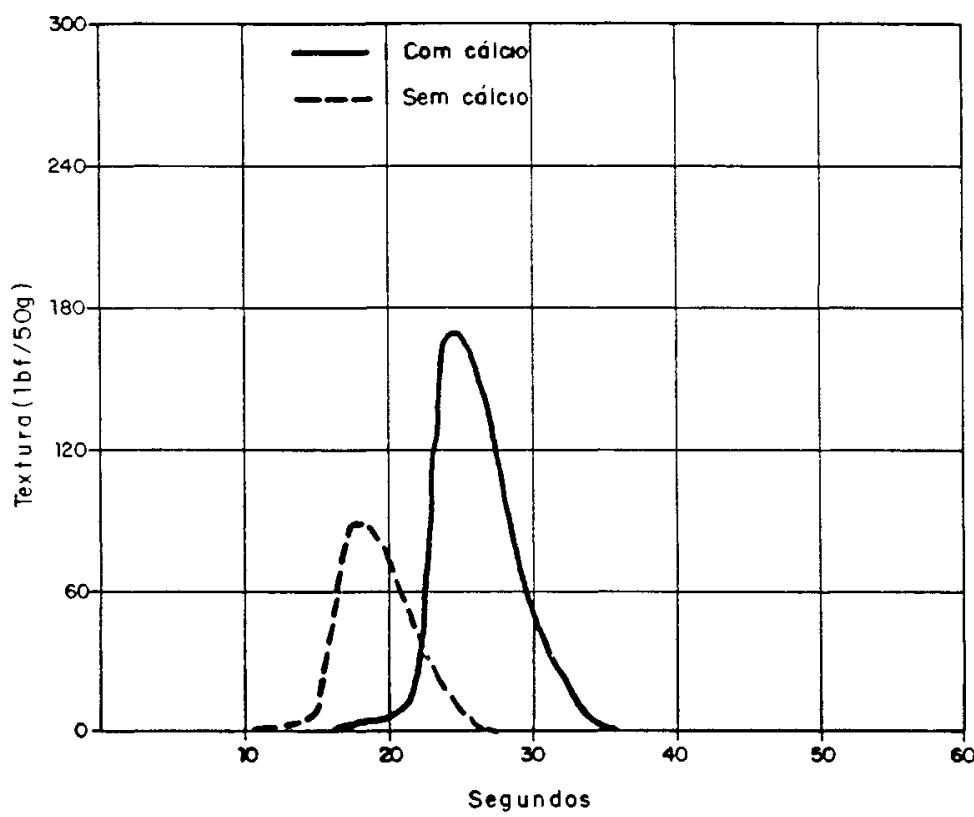

Figura 10 - Curvas típicas obtidas no "Shear Press" de couve-flor acidificada (ácido acético) e processada. 
TABELA 3 - Análises físicas e químicas da couve-flor processada.

\begin{tabular}{|c|c|c|c|c|c|c|}
\hline \multirow{3}{*}{ Análises } & \multicolumn{6}{|c|}{ Tratamentos } \\
\hline & \multicolumn{2}{|c|}{$\mathrm{AC}$} & \multicolumn{2}{|c|}{ AT } & \multicolumn{2}{|c|}{$\mathbf{A L}$} \\
\hline & $\mathbf{I}$ & II & I & II & I & II \\
\hline Peso líquido (g) & 806,36 & 807,57 & 809,44 & 808,35 & 809,52 & 817,19 \\
\hline Peso drenado $(\mathrm{g})$ & 368,50 & 360,63 & 364,30 & 363,03 & 359,67 & 367,78 \\
\hline Vácuo (pol Hg) & 11,00 & 12,70 & 13,20 & 16,50 & 13,00 & 15,00 \\
\hline Brix de equilibrio & 2,35 & 2,27 & 2,35 & 2,15 & 2,30 & 2,17 \\
\hline pH de equilibrio & 4,38 & 4,14 & 4,48 & 4,34 & 4,34 & 4,23 \\
\hline Acidez total (\%) & 0,161 & 0,150 & 0,127 & 0,123 & 0,166 & 0,153 \\
\hline Aspecto da salmoura & 1,5 & 1,0 & 1,0 & 1,0 & 1,5 & 1,5 \\
\hline \multirow[t]{2}{*}{ Aspecto interno da lata } & 1,0 & 1,5 & 1,0 & 1,0 & 1,5 & 1,0 \\
\hline & \multicolumn{6}{|c|}{ Tratamentos } \\
\hline \multirow[t]{2}{*}{ Análises } & \multicolumn{2}{|c|}{ AA } & \multicolumn{2}{|c|}{$\mathrm{AM}$} & \multicolumn{2}{|c|}{ FE } \\
\hline & I & II & I & II & I & II \\
\hline Peso líquido (g) & 808,48 & 813,08 & 798,25 & 816,14 & 802,99 & 793,93 \\
\hline Peso drenado $(\mathrm{g})$ & 369,03 & 365,24 & 368,18 & 360,73 & 381,41 & 359,83 \\
\hline Vácuo (pol Hg) & 13,20 & 14,00 & 16,20 & 13,00 & 15,20 & 16,70 \\
\hline Brix de equilibrio & 2,45 & 2,12 & 2,27 & 2,30 & 2,00 & 1,95 \\
\hline pH de equilíbrio & 4,41 & 4,33 & 4,46 & 4,29 & 4,41 & 4,40 \\
\hline Acidez total (\%) & 0,180 & 0,174 & 0,141 & 0,134 & 0,144 & 0,148 \\
\hline Aspecto da salmoura & 1,0 & 1,0 & 1,5 & 1,0 & 4,0 & 4,0 \\
\hline Aspecto interno da lata & 1,0 & 1,0 & 1,5 & 1,5 & 1,0 & 1,0 \\
\hline
\end{tabular}

I = sem cálcio; $\quad$ II = com cálcio

\section{AGRADECIMENTOS}

Agradecemos à FAPESP o auxílio concedido para o desenvolvimento do trabalho.

\section{REFERENCIAS BIBLIOGRÁFICAS}

AYRES, J.C. Processed meats. In: MEAT INDUSTRY RESEARCH CONFERENCE, 1975, Arlington. Proceedings... Arlington : American Meat Institute Foundation, 1975. p.103-113.
DAWSON, E.H. Sensory testing quide for panel evaluation of food and beverages. Food Technology, Chicago, v.16, n.8, p.25-31, 1964.

FERMENTATION MAY ANSWER NEEDS FOR NATURAL FOODS, LOW-ENERGY PROCESS. Food Product Development, Chicago, v.14, n.9, p. $48,1980$.

FLEMING, H.P.; McFEETERS, R.F. Use of microbial cultures: vegetable products. Food Technology, Chicago, v.35, n.1, p.84, 1981 . 
FOOD AND DRUG ADMINISTRATION. Pickled, fermented, acidified and low-acid foods. Federal Register. Washington, v.43, p.30441-30461, 1976.

FRAZIER, W.C. Food microbiology. 2.ed. New York: McGraw-Hill, 1967. 537p.

GIRARDOT, N.F.; PERYAM, D.R.; SHAPIRO, R. Selection of sensory testing panels. Food Technology, Chicago, v.6, n.4, p.140-143, 1952.

GOMES, F.P. Curso de Estatística Experimental. 5.ed. São Paulo : Nobel, 1973. 468p.

GRANER, M. Conservas caseiras. O Estado de São Paulo, São Paulo, 7 nov. 1976. Suplemento Agrícola, v.21, n.1119, p.13.

KARMAS, E. Nutricional aspects of food processing methods. In: HARRIS, R.S.; KARMAS, E. (Ed.). Nutricional Evaluation of Food Processing. 2.ed. Westport : AVI, 1975. p 11.

KONIGSBACHER, K.S. How the government vews sensory evaluation. Food Techonology. Chicago, v.32, n.11, p 64-66, 1978

KOSUP, P.; SISTRUNK, W.A. Quality attributes of fermented and acıdified green beans. Journal Fond of Science, Chicago, v 47, p 1001-1005, 1982.

KOTZEKIDOU, P.; ROUKAS, T. Quality characteristics of fermentated and acidified canned okra. Iebensmittel Wissenschaft und Teclunologie. Zurich, v,20, p.300-304, 1987.

LARMOND, E. Laboratory methods for sensory evaluation of food. Ottawa, Canada Department of Agriculture, 1977. 73p. (Publication, 1637).

MARTIN, S.L. Selection and training of sensory judges. Food Techonology, Chicago, v.27, n.11, p.22-26, 1973.

Sci. agric., Piracicaba. 50(1):127-139, fev./maio, 1993
NOGUEIRA, J.N. Estudo sobre o processamento do palmito (Euterpe edulis Mart.) por apertizaçāo. Piracicaba, 1979, 114p. Tese (Livre-Docência). Escola Superior de Agricultura "Luiz de Queiroz", Universidade de São Paulo.

SAWER, F.M. Interaction of sensory panel and instrumental measurement. Food Techonology, Chicago, v.25, n.3, p.51-52, 1971.

SIMONS, R.L.; HOWE, R.N.; KLOMPARENS, K. Cut salt cost up to $3 \mathrm{c} . / \mathrm{lb}$. Food Processing, Chicago, v.16, p.44-45, 1955.

SUPRAN, M.K.; POWERS, J.J.; RAO, P.V.; DORNSERTER, T.P.; KING, P.H. Comparision of different organic acids for the accidification of Canned Pimientos. Food Techonology, Chicago, v.215, p.117-123, 1966

VAN BUREN, J.P. Adding calcium to snap beans at different stages in processing: calcium uptake and texture of the canned product. Food Technology, Chicago, v.22, n.6, p.790, 1968.

VAN BUREN, J.P. The chemistry of texture in fruits and vegetables. Journal of Texture Studies, Trunbull, v.10, p.1, 1979.

ZAPATA, M.M.; QUAST, D.G. Curvas de titulação do palmito-doce (Euterpe edulis Mart.). Coletánia do Instituto de Tecnologia de Alimentos, Campinas, v.6, n.11, p.167-187, 1975

Trabalho entregue para publicação em 03.02 .92

Trabalho aprovado para publicação em 24.06.92 